\title{
Patrimônio Cultural e Memória do MERCOSUL: Serra da Barriga/Alagoas - Brasil.
}

\author{
Patrimônio Cultural del MERCOSUR: Serra da Barriga/Alagoas - Brasil. \\ MERCOSUl Heritage: Serra da Barriga/Alagoas - Brasil.
}

\author{
Maria de Fátima Bento Ribeiro ${ }^{1}$ \\ Alan Dutra de Melo ${ }^{2}$
}

\begin{abstract}
Resumo
O objetivo deste artigo é refletir sobre o reconhecimento, no ano de 2017, da Serra da Barriga - Estado de Alagoas/Brasil como patrimônio cultural do MERCOSUL. Ação impulsionada pela Venezuela, com apoio do Equador e do Brasil, na reunião da Comissão de Patrimônio do Mercosul realizada em Jaguarão no ano de 2015. $\mathrm{O}$ reconhecimento dos remanescentes de "Cumbes, quilombos e palenques do Mercosul - La geografia del cimarronaje" foi proposto como forma de preservar a memória de resistência e luta pela liberdade dos negros escravizados nos países que compõem o bloco de integração regional. Nesse sentido, este estudo aponta para o que concebemos como dever de memória que acompanha o reconhecimento dos bens como integrantes do Patrimônio Cultural, pertencentes aos cidadãos e respectivos países, territórios, regiões, municípios onde estiverem inseridos, somado à necessidade de reflexão acerca de sua valorização e reconhecimento.
\end{abstract}

Palavras-Chave: Patrimônio Cultural. Memória. MERCOSUL. Serra da Barriga.

\section{Resumen}

El objetivo de este artículo es reflexionar sobre el reconocimiento, en el año de 2017, de la Serra da BarrigaEstado de Alagoas/Brasil como patrimonio cultural de MERCOSUR. Acción impulsada por Venezuela, con apoyo de Ecuador y de Brazil, en la reunión de la Comisión de Patrimonio del Mercosur, realizada en Jaguarão, en el año de 2015. El reconocimiento de los remanescientes de "Cumbes, quilombos e palanques do Mercosul- La geografia del cimarronaje" fue propuesto como forma de preservar la memoria de resistencia y lucha por la libertad de los negros esclavizados en los países que componen el bloque de integración regional. En ese sentido, este estudio apunta para lo que concebimos como deber de memoria que acompanha el reconocimiento de los bienes como integrantes del Patrimonio Cultural, pertenecentes a los ciudadanos y respectivos países, territorios, regiones, municipios donde estén insertados, sumado a la necesidad de reflexión a cerca de su valoración y reconocimiento.

Palabras claves: Patrimonio Cultural. Memoria. MERCOSUR. Serra da Barriga

\begin{abstract}
The article's objective is to reflect about the recognition of the Serra da Barriga, localized on the Alagoas State/Brazil, as cultural heritage of MERCOSUL in the year 2017. It is an action by Venezuela with the support of Ecuador and Brazil, at the meeting of the MERCOSUL Heritage Committee, held in Jaguarão, Rio Grande do

\footnotetext{
${ }^{1}$ Dr $^{\mathrm{a}}$ Maria de Fátima Bento Ribeiro; Pós-Doutoranda em Sociedade, Cultura e fronteiras; Universidade Estadual do Oeste do Paraná - UNIOESTE; Prof ${ }^{\text {a }}$ Associada Universidade Federal de Pelotas - UFPel; Bacharelado em Relações Internacionais; Pelotas, RS, Brasil; E-mail: mfabento@ hotmail.com.

${ }^{2}$ Dr. Alan Dutra de Melo; Universidade Federal do Pampa - Unipampa; Prof ${ }^{\circ}$ Adjunto; Cursos de Tecnologia em Gestão do Turismo e Bacharelado em Produção e Política Cultural; Jaguarão, RS, Brasil; E-mail: alanmelo@unipampa.edu.br.
} 
Sul, in the year 2015. The recognition of the remaining "Cumbes, quilombos e palenques do Mercosul - La geografia del cimarronaje", it was proposed as a way to preserve the memory of resistance and struggle for freedom of the enslaved blacks in the countries that make up the regional integration group. In this sense, this study points to what we conceive as to duty of memory that follows the recognition of assets as integrants of the Cultural Patrimony of the subjects and his respective countries, territories, regions or cities where they are inserted, it together with the need to reflections on their valuation and recognition.

Keywords: Cultural Heritage. Memory. MERCOSUL. Serra da Barriga

\section{Introdução}

São patrimônios culturais do MERCOSUL os seguintes bens: a ponte internacional Barão de Mauá, localizada em Jaguarão, Rio Grande do Sul, Brasil e Rio Branco, no Uruguai; a região das missões, que abrange cinco países (Brasil, Argentina, Paraguai, Uruguai e Bolívia); A pajada ou "payada", como primeiro bem imaterial, e, recentemente, a Serra da Barriga $^{3}$, em Alagoas, ganhou reconhecimento internacional ao ser incluída na lista de patrimônio cultural do Mercosul. A certificação foi concedida no dia 11 de novembro de 2017.

O documento apresentado pela delegação do Brasil, no processo de tombamento da Serra da Barriga para obtenção do reconhecimento como patrimônio cultural do Mercosul considera que o "quilombo dos palmares representa a história de resistência ao modelo colonial imposto no território brasileiro, durante os séculos XVII e XIX" (cf. Dossiê, 2017, p.13). De acordo com o Dossiê, o reconhecimento da Serra da Barriga como Patrimônio Cultural em 1986, por lei federal de tombamento, "representou um importante passo do governo brasileiro de reconhecimento quanto ao estabelecimento de políticas afirmativas e do fortalecimento de referências culturais negras e afro-brasileiras na construção identitária do país" (2017, p.13). Portanto, essa luta por liberdade, cujo um dos ápices foi o Quilombo de Palmares que funcionou por mais de um século como território de resistência, é reafirmada com o reconhecimento do território como patrimônio cultural.

O Brasil e o Equador apresentaram os dossiês de candidaturas na XIV Reunião do Mercosul, que aconteceu em Buenos Aires, em que a CPC aprovou a inclusão da Serra da Barriga, junto com "Cimarrojane Cultural: El Patrimonio Cultural Inmaterial del Pueblo Afrodescendiente em el Ecuador", no âmbito de Cumbes, Quilombos y Palenques". Com relação aos temas do patrimônio cultural, Ramon Gutierrez propõe uma reflexão partindo da experiência latino-americana que segundo o autor é "diferente da experiência eurocêntrica"

\footnotetext{
${ }^{3}$ Localiza-se no município de União de Palmares, Zona da Mata do Estado de Alagoas, Brasil. Ocupa uma área de aproximadamente $27,92 \mathrm{Km}^{2}$.
} 
É importante destacar que Serra da Barriga faz parte do dossiê de candidatura que foi apresentado pela Venezuela, Equador e Brasil, "La geografia del Cimarrone: Cumbes, Quilombos y Palenques del MERCOSUR”, na XIII reunião da Comissão do Patrimônio do Mercosul, realizada em Colônia do Sacramento no Uruguay em maio de 2016. Encontram-se os seguintes sítios:

(...) por Brasil, "Serra da Barriga, parte más acantilada"(Estado do Alagoas); por Ecuador, Província de Esmeraldas; y por Venezuela, Taría (Estado de Alagoas); por Ecuador, Província de Esmeraldas; y por Venezuela, Taría (Estado Yaracuy), Ocoyta (Estado de Miranda), Cata (Estada Aragua), Carayaca (Estado Vargas), Siquisque (Estado Lara) Caño del Caracol (Estado Guárico), Birongo (Estado Miranda), Capaya (Estado Miranda), Santa Maria de la Chapa (Estado Falcón) y Macuquita (Estado Falcón). (ATA XIII CPC, IPHAN,2016).

Compreendendo a história à luz dos seus protagonistas, o Patrimônio Cultural $^{4}$ pode amalgamar ideias e ações no contexto da América Latina, e, mais especificamente, nos países do MERCOSUL ${ }^{5}$. Assim como no Brasil, outros países que formam o Mercosul possuem uma história marcada pela presença da cultura de matriz africana, apresentando traços de uma cultura compartilhada na América do Sul.

Em 2013, a Organização das Nações Unidas- ONU aprovou a Década Internacional de Afrodescendentes, de 2015 a 2024, com o tema reconhecimento, justiça e desenvolvimento. Um dos focos em destaque é justamente a promoção de maior conhecimento e respeito aos diversos patrimônios culturais e contribuições dos afrodescentes.

O reconhecimento da Serra da Barriga, no Brasil, como patrimônio cultural do Mercosul, no âmbito internacional é um reflexo dessas ações e vem reafirmar a necessidade da valorização da história na perspectiva das lutas de resistências a dominação. No âmbito regional é um bem que possui referências culturais além fronteira de um país, de acordo com decisão 55/12 do Mercosul, constitui-se em importante "fator para integração".

No âmbito nacional, é fruto da luta principalmente do movimento negro que reivindicavam o espaço para a construção do Memorial Zumbi. ${ }^{6}$ Em 1988 a Serra da Barriga,

\footnotetext{
${ }^{4}$ Os critérios de reconhecimento para qualquer bem de natureza material e/ou imaterial como Patrimônio Cultural do Mercosul de acordo com a Decisão do Mercosul n.55/12 são que: Manifeste valores associados a processos históricos vinculados aos movimentos de autodeterminação ou expressão comum da região perante o mundo; Expresse os esforços de união entre os países da região;

Esteja diretamente relacionado a referências culturais compartilhadas por mais de um país da região;

Constitua fator de promoção da integração dos países, com vistas a um destino comum.

${ }_{5}^{5}$ Mercado Comum do Sul (MERCOSUL) foi criado em 26/03/91 com a assinatura do Tratado de Assunção no Paraguai. Os membros fundadores são: Brasil, Argentina, Uruguai, Paraguai. Como o tratado previa adesão de outros países o primeiro foi a entrada da Venezuela (atualmente suspensa), e a Bolívia, em andamento. Todos os demais países sul-americanos estão vinculados ao Mercosul como países associados.

${ }^{6}$ O Parque Memorial do Quilombo dos Palmares foi implantado em 2007.
} 
foi declarada como monumento nacional pelo Decreto n.95.855 de 21 de março, pela importância histórica do sitio.

Sabe-se que a escolha dos espaços de memória por parte das instituições nacionais podem servir para manutenção de representação de poder. Sobre isso, cita-se Antônio P. Ribeiro, em seus estudos sobre memórias:

Os museus não são arquivos, tão pouco conjuntos de acervos reunidos. São sobretudo representação de poder segundo propósitos que são legitimados por uma determinada epistemologia e que, num contexto nacional, tem por objetivo produzir e difundir uma determinada memória de identificação nacional. Podem ainda ser decorrentes de subalternidades que se legitimaram como narrativas incontornáveis num período de democracias cujos melhores exemplos são alguns museus de memórias e dos direitos humanos e alguns museus afrodescendentes" (2018, p.1).

O interesse era gerar uma candidatura em conjunto com outros países do bloco de "forma a dar visibilidade à presença e à contribuição dos afrodescendentes da região". Tal disposição partiu da delegação da Venezuela na Comissão do Patrimônio Cultural do Mercosul-CPC, considerando o interesse e importância do tema (cf. ata 01/2015) durante a reunião que aconteceu na cidade de Jaguarão, Brasil, no ano de 2015, ao buscar a realização do reconhecimento como patrimônio do Mercosul dos "Cumbes, Quilombos e Palenques do Mercosul, a geografia do Cimarrone", dando visibilidade aos lugares que registram os espaços de vida e luta dos povos africanos trazidos para América do Sul.

A importância do patrimônio para o reconhecimento e valorização das identidades regionais, de acordo com documentos produzidos pela CPC, pode constituir fator de integração regional, em que manifestações culturais compartilhadas, histórias e memórias, venham a facilitar o diálogo, aproximação e a construção de projetos comuns. De acordo com Erivaldo Oliveira, responsável pela administração do Parque Memorial Quilombo dos Palmares, é uma valorização da cultura afro-brasileira "o reconhecimento do Mercosul é muito simbólico para o movimento negro, demonstra o respeito pelos nossos ancestrais que tanto lutaram pela liberdade". 7

São espaços que marcaram história e a memória da luta e da resistência de suas experiências históricas, que na contemporaneidade são resignificados pelos afrodescentes da América do Sul. Também, é uma forma ainda que tardia do reconhecimento como parte da história nacional, dos movimentos de autodeterminação, um caminho para compreensão e inclusão de políticas.

\footnotetext{
${ }^{7}$ http://www.cultura.gov.br/noticias-destaques/-/asset publisher/OiKX3xIR9iTn/content/serra-da-barriga-eescolhida-patrimonio-cultural-do-mercosul/10883. Acesso em 22.09.2018
} 
RELACult - Revista Latino-Americana de Estudos em Cultura e Sociedade

Revista Latinoamericana de Estudios en Cultura y Sociedad | Latin American Journal of Studies in Culture and Society V. 04, nº 02, maio-ago., 2018, artigo n 901 | relacult.claec.org | e-ISSN: 2525-7870

\section{O direito à memória nacional}

O direito à memória como prerrogativa social e inclusive constitucional é um tema atual. Trata-se do reconhecimento como parte constituinte da história regional, nacional, dado o tombamento da Serra da Barriga pelo Instituto do Patrimônio Histórico e Artístico Nacional em 1986, reconhecendo bens do conjunto histórico-paisagístico como parte da formação da história do Brasil e da América do Sul. Sobre o direito à memória, observar Chaui (2006), e especificamente sobre o tema do escravismo na sociedade colonial e imperial, e as disputas de memórias sobre este tema ver Maestri (2009).

De acordo com o Dossiê, o reconhecimento pelo governo federal em 1986, representou "um importante passo de reconhecimento quanto ao estabelecimento de políticas afirmativas e do fortalecimento de referenciais negras e afro-brasileiras na construção identitária do país" (2017, p.13).

A constituição Federal de 1988 em seu artigo 216 ampliou a noção de Patrimônio Cultural ao inserir o reconhecimento de bens materiais e imateriais, com o estabelecimento de direitos e a valorização dos referencias da cultura afro-brasileira, indígena e quilombola. Para Ulpiano de Menezes, ao examinar a constituição de 1988 com relação ao Patrimônio Cultural, o deslocamento do valor da matriz cultural é outro elemento importante nas questões do campo do patrimônio, "vê-se que sua grande novidade, no tema, foi deslocar do estado para a sociedade e seus segmentos a matriz do valor cultural”, chamando atenção para que os valores culturais, fossem repensados a luz das "práticas culturais e seus praticantes".

Importante destacar que no Brasil, de acordo com o trabalho de Petronio Domingues e Flavio Gomes:

\footnotetext{
Na década de 1970, houve uma revalorização da ideia de quilombo no imaginário racial brasileiro e na trajetória dos movimentos sociais. Apropriada em narrativas da memória e transmitida de geração a geração através da oralidade, a ideia de quilombo foi ressignificada como referência histórica fundamental, tornando-se, assim, um símbolo no processo de construção de afirmação social, política, cultural e identitária do movimento negro contemporâneo no Brasil. Se antes era visto com resistência ao processo de escravização do negro, a partir dali se converteu em símbolo, não só da resistência pretérita, como também de luta no tempo presente pela reafirmação da herança afro-dispórica e busca de um modelo brasileiro capaz de reforçar a identidade étnica cultural”. (2013, p.10)
}

$\mathrm{Na}$ esteira dos processos de reivindicação dos movimentos sociais se reconhece o legado cultural que no passado haviam sido negados como formadores da identidade nacional, de acordo com Edgar Saldatori De Decca, ao analisar as narrativas histórico-literárias da identidade nacional diz "tanto os habitantes naturais das américas, os ameríndios, como a 
população negra transplantada da África, não poderiam ser portadores da ideia de identidade nacional, por que não foram considerados aptos para se emancipar” (2002, p. 94).

De Decca (2002), ao refletir sobre a identidade na América, remete ao sentimento de desterro que caracterizou a experiência de colonização americana. É também sobre esta possibilidade, de buscar, de reconhecer identidades reivindicatórias como um patamar de amadurecimento democrático que se reconhece a Serra da Barriga como Patrimônio do Mercosul.

É necessário desocultar essas narrativas para criar um novo patamar, o reconhecimento do território da Serra da Barriga, não como lugar para onde convergem as diferentes formas de institucionalidade, mas sim, como território livre para o pensamento e a construção do saber, como paisagem humana e cultural, que deve ser vista e ouvida.

E deve-se destacar, sobretudo, nesse espaço de memória e resistência, "a retomada da Serra da Barriga" (cf. SALOMÃO, 2008, p.45), no começo da década de 1980 pelo movimento negro brasileiro, conforme segue:

Em abril de 1980, militantes negros, intelectuais e funcionários da Fundação PróMemória, do Ministério da Cultura, fizeram a retomada da Serra da Barriga e firmaram as bases para a fundação do Memorial Zumbi, criado em 20 de novembro daquele ano, dia e morte de Zumbi dos Palmares. Do ato de Fundação do Memorial - com o primeiro ritual de subida - que se repete até os dias de hoje, participaram dezenas de negros(as), dentre eles a saudosa Lélia Gonzales e Beatriz Nascimento, autoridades governamentais e universitárias, além dos afoxés Ilê Aiyê, Malê, Orunmilá e Baduê. E personalidades negras: mãe Hilda, que realizou os rituais religiosos e Abdias Nascimento que discursou. (cf. SALOMÃO, 2008, p.45).

Portanto, nota-se a busca pelo reconhecimento e valorização desse espaço, marcado pela experiência de resistência do afrodescendente em busca de autonomia e identidade. Trata-se de um enclave, voltado para a resistência e a ocupação territorial, que agora mantém e amplia a sua abertura para o Brasil, o Mercosul e o mundo. Sobre a relevância na atualidade que envolve patrimônio, memória e história, como reivindicação e recurso, Rubino (2011, p. 393), assinala que patrimônio passou a ser "um lugar compartilhado, um ponto de encontro entre disciplinas, saberes e políticas”.

É preciso descolonizar o Patrimônio Cultural, de suas amarras institucionais, porém, sem negar a sua relevância. Imputa-se a identificação de seu potencial como ponto elevado para construir e debater a cidadania. A cidadania que pode aflorar da Serra da Barriga permite repensar o conhecimento sobre a memória da escravidão, ampliando a capacidade narrativa e 
potencializando a criação e o debate dentro do leque de possibilidades que aflora a partir desse Patrimônio Cultural.

Marcas da história e da memória dos afrodescendentes presentes não só nesse local, mas na política voltada para o reconhecimento dos territórios quilombolas no Brasil, por exemplo, trazem à tona o debate entre memória e esquecimento, bem como a forma de reparação do passado onde existia a escravidão pelo presente, que vez por outra nega as diferenças e as desigualdades sociais estruturantes no Brasil. Relega-se, assim, aos grupos historicamente excluídos, não só o lugar na história, mas, sobretudo, um presente venturoso, o que estabelece uma posição incerta do futuro.

"O esquecimento é um dos principais fatores que moldam a lembrança nacional" (Hamilton, 2006, p.87), por mais que a monumentalização da memória possa provocar o esquecimento o trabalho da história pode ser uma forma de evitar o esquecimento (De Decca, 2001, p.32). Nessa direção, acredita-se que a apresentação da Venezuela, ao propor a inclusão de vários sítios no dossiê para candidatura como patrimônio do Mercosul, em que emergem a presença, experiência histórica, marcados por uma cultura hibrida de afrodescendentes na região, gera notoriedade.

Espera-se uma retomada crítica do reconhecimento do passado, "mais importante que o passado é sua influência sobre as atitudes culturais do presente" (SAID, 2011, p.54). Nesse sentido, também Candau (2012), apontando a necessidade de que se busque, nas suas palavras, "a justa memória", ou seja, um ponto de equilíbrio, entre a lembrança e o esquecimento. E outro autor importante, para que se pense sobre as emergências das identidades, é Hall (2011), como lembra o autor, as identidades são construções culturais a partir de processos de representação.

É importante destacar como mencionado anteriormente que o conjunto histórico e paisagístico da serra da Barriga foi reconhecido como "Patrimônio Histórico e Artístico Nacional”, pelo Instituto do Patrimônio Histórico Artístico Nacional - IPHAN, no ano de 1985/86, inscritos nos livros Tombo Histórico e Livro do Tombo Arqueológico, Etnográfico e Paisagístico.

Conforme mencionado em seu dossiê Serra da Barriga (2017, p.99), a gestão é da Fundação Palmares, que mantem ações de conservação e manutenção da área do Parque Memorial Zumbi dos Palmares. O Comitê Gestor da Serra da Barriga conta com representantes de comunidades capoeiristas, religiões de matriz africana, quilombolas, junto a membros de instituições parceiras das três esferas do governo, conforme portal do IPHAN, 
onde também se identifica nota que almeja o reconhecimento do local como Patrimônio da Humanidade junto à UNESCO.

\title{
3. Memória e Patrimônio: das vanguardas da memória ao desejo da ação:
}

Deve-se ponderar, no entanto, que seria mais oportuno, por parte do Brasil, inserir mais de um sítio $^{8}$, seguindo o exemplo da Venezuela. Não seria o Cais Valongo, no Rio de Janeiro, reconhecido como Patrimônio da Humanidade, também patrimônio do Mercosul?

Ainda nesse sentido, como exemplo, tem-se no Rio Grande do Sul, o trabalho "A Paisagem Cultural e a Constituição de um mapa etnográfico do distrito de Quilombo na Serra do Tapes em Pelotas", de autoria de Ávila et. al (2014). O estudo versa sobre as memórias da experiência da escravidão e das experiência quilombola.

\begin{abstract}
O presente trabalho procura relatar o processo de constituição do mapa etnográfico que versa sobre as memórias da experiência da escravidão e da experiência quilombola dos moradores da zona rural de Pelotas-RS. Para tal, foi realizada uma pesquisa bibliográfica e em documentação primária sobre a escravidão que ocorreu na Cidade durante o século XIX, bem como em relação ao movimento de resistência quilombola encabeçado por Manuel Padeiro neste período. No que se refere à pesquisa de campo, coletamos informações através da metodologia de entrevista e fotografias junto aos moradores do Distrito de Quilombo, do Distrito Triunfo e das Comunidades Negras Rurais do Alto do Caixão e do Algodão. Pretendemos através da constituição deste mapa demonstrar que o Patrimônio Cultural relacionado à etnia negra na região se faz presente em suas memórias através da Paisagem Cultural, ou seja, na denominação da estrada, do arroio e do próprio distrito - Quilombo; no morro do Quinongongo, com sua flora e fauna exuberantes, ou ainda nas ruínas de uma antiga senzala. (ÁVILA et. al., 2014, p.1).
\end{abstract}

Os espaços da presença e história do afrodescendente estão em todo o Brasil e não parece razoável eleger um centro apenas, embora este seja muito importante. Cabe destacar a

\footnotetext{
${ }^{8}$ Como exemplo, tem-se na Bahia, o Terreiro da Casa Branca do Engenho Velho, tombado pelo instituto em 1984.
} 
liderança da Venezuela, conforme descrito por Heiden (2017, p. 226), para a inclusão da temática como Patrimônio do Mercosul:

\begin{abstract}
Contreras apresentou diversos aspectos para o reconhecimento de tal iniciativa, dentre eles a inspiração em movimentos de combate ao racismo no continente africano, argumentando que esses sítios seriam símbolos da diversidade do patrimônio cultural latino americano, considerando que à partir dos Cumbes, Quilombos e Palenques venezuelanos teriam surgido muitas tradições culturais de toda ordem à cultura dos afrodescendentes. A Venezuela estaria disposta à valorizar os locais vinculados à história da etnia, como forma, de valorização também do saber surgidos nesses locais. Baseado nessas ideias, foi solicitado o reconhecimento na XI CPC, como Patrimônio Cultural do Mercosul, para o conjunto de sítios apresentados na proposta do país. (Heiden, 2017, p.226).
\end{abstract}

Com relação à posição do Brasil frente aos desafios do tema, ao incluir apenas um local como referência, fica o questionamento: poderia ter sido aberto um edital para outras candidaturas?

De acordo com Mbembe (2014, p.105), a burocracia emerge como um dispositivo de dominação, ao racializar os sujeitos históricos de tal modo que remete aos limites do cuidado, ao se arbitrar tais situações a partir apenas do viés estatal. Dessa forma, patrimônio e memória dependem de uma disposição ética para ação como inspiração. Conforme Mbembe (2014, p. 163), o tempo do futuro é o da esperança e o do presente é o do dever. Nesse ínterim, Mbembe assinala: "existe a probabilidade de esta função de evocação ser libertadora, se não ceder à nostalgia ou à melancolia (MBEMBE, 2014, p.164).

Com o debate sobre o ato declaratório da Serra da Barriga como patrimônio cultural do Mercosul, espera-se trazer contribuições necessárias que se proponham a posicionar essa importante discussão no seu devido lugar na atualidade. Com essa discussão espera-se, portanto, ter fornecido subsídios para reflexão sobre o lugar do patrimônio e da memória na contemporaneidade, almejando-se o diálogo com a disposição ética para a ação.

\title{
4.Conclusões
}

As conclusões desse estudo apontam para a importância sobre a recente declaração da área da Serra da Barriga como Patrimônio Cultural do Mercosul. Desse modo, em concordância com o que diz Mbembe, opta-se pela necessidade para a ação, isto é, a metáfora de uma história que há de vir.

Por fim, por justa memória, deve ser lembrada a trajetória do movimento negro, em Palmares, desde 1980, conforme afirma Wally Salomão, "Contra o racismo, pela cidadania e a 
vida", pois "a felicidade do negro é uma felicidade guerreira”. Assim como o reconhecimento do local como patrimônio nacional, realizado pelo IPHAN logo em seguida.

\section{Referências}

ÁVILA, C. B., RIBEIRO, M. F. B. A paisagem cultural e a constituição de um mapa etnográfico do Distrito de Quilombo na Serra dos Tapes-Pelotas-RS. Fonte: Revista Fórum Patrimônio Ambiente Construído e Ambiente Sustentável. V. 7. N.1. 2014. p.1-19.

CANDAU, J. Memória e Identidade. 1.ed. São Paulo: Contexto, 2012.

CHAUI, M. Cidadania Cultural. São Paulo: Editora Fundação Perseu Abramo, 2006.

DECCA, E. S. Tal pai, tal filho? Narrativas histórico-literárias da identidade nacional. Projeto História. Revista do Programa de Estudos Pós-Graduados de História. São Paulo. n. 24/junho de 2002. p.87-111.

. O Holocausto. Temas \&Matizes n.01. Cascavel: EDUNIOESTE, 2001.

GARCIA, J. 25 anos 1980-2005: movimento negro no Brasil. 2.ed. - Brasília, DF: Fundação Cultural Palmares, 2008.

HALL, S. A identidade cultural na pós-modernidade. 11.ed. Rio de Janeiro: DP\&A, 2011.

HEIDEN, R. Argentina, Uruguai e Mercosul: Instituições normativas e políticas patrimonias no contexto de uma União Aduaneira. Tese (doutorado). Programa de Pós-Graduação em Memória Social e Patrimônio Cultural. Universidade Federal de Pelotas. Instituto de Ciências Humanas. Pelotas, 2017.

HUYSSEN, A. Culturas do passado-presente modernismos, artes visuais, políticas da memória. [Coordenação Tadeu Capistrano]; tradução Vera Ribeiro - 1.ed. - Rio de Janeiro: Contraponto: Museu de arte do Rio, 2014.

INSTITUTO DO PATRIMÔNIO DO HISTÓRICO E ARTÍSTICO NACIONAL - IPHAN. Disponível em: http://portal.iphan.gov.br/. Acesso em 10/05/2018.

INSTITUTO DO PATRIMÔNIO DO HISTÓRICO E ARTÍSTICO NACIONAL - IPHAN. Dossiê de tombamento de Candidatura da Serra da Barriga. Parte Mais Alcantilada Quilombo dos Palmares e Patrimônio Cultural do MERCOSUL Marcelo Brito coord. São Carlos: Ed. $2017 . \quad$ cubo, Disponível em: http://portal.iphan.gov.br/uploads/ckfinder/arquivos/Dossie_serra-da-barriga.pdf. Acesso em $\underline{11 / 05 / 2018 .}$.

MAESTRI, M. A reabilitação da ordem escravista: determinação, autonomia, totalidade e parcialidade da história. In. Grilhão Negro: ensaios sobre a escravidão colonial no Brasil. Mario Maestri e Helen Ortiz (orgs). Ed. Universidade de Passo Fundo, 2009.

MBEMBE, A. Crítica da razão negra. Lisboa - Portugal. Antígona Editora. 3.ed., 2014. 
MENESES, U. B. O campo do patrimônio cultural: uma revisão de premissas. Disponível em: http://portal.iphan.gov.br/uploads/ckfinder/arquivos/Texto\%204\%20\%20MENESES.pdf. Acesso em 10/05/2018.

MERCOSUL. N. 01/2015. XI Reunião da Comissão do Patrimônio Cultural do Mercosul (27, 28, 29 de maio de 2015). Jaguarão RS. República Federativa do Brasil. Disponível em: http://portal.iphan.gov.br/pagina/detalhes/1120/. Acesso em 10/05/2018.

MERCOSUL. N. 01/2016. XIII Reunião da Comissão do Patrimônio Cultural do Mercosul (03 e 04 de maio de 2016). Colonia del Sacramento. República Oriental del Uruguai. Disponível em: http://portal.iphan.gov.br/pagina/detalhes/1120/. Acesso em 10/05/2018.

RIBEIRO, A. O impossível museu. In. http://www.buala.org/pt/a-ler/o-impossivel-museu acesso em 15/10/2018.

RIBEIRO, M.F.B, FERNANDES, C.C.C. Mercosul 25 anos: cultura, patrimônio e identidade. p. 107-136. In. PENNAFORTE, Charles. Ribeiro, Maria de Fátima Bento. Mercosul 25 anos: avanços, impasses e perspectivas. Pelotas: Centro de Integração do Mercosul-UFPEL/Grupo de Pesquisa CNPq Geopolítica e Mercosul/Centro de Estudos em Geopolítica e Relações Internacionais/Cenegri, 2016.

RUBINO, S. Patrimônio, história e memória como reinvindicação e recurso. In. Agenda Brasileira: temas de uma sociedade em mudança. Org. André Botelho e Lilia Moritz Schwarcz (orgs). São Paulo: Companhia das Letras, 2011.

SAID, Edward W. Cultura e Imperialismo. São Paulo: Companhia das Letras, 2011.

THOMPSON, Alistair et al. Memória e Tradição. IN. Usos e abusos da história Oral. AMADO, Janaina; FERREIRA, Marieta M. 8. Ed. Rio de Janeiro: Editora FGV,2006. 